\title{
Reading and Language in the Early Grades
}

\section{Citation}

Snow, Catherine E., and Timothy J. Matthews. 2016. "Reading and Language in the Early Grades." The Future of Children 26 (2): 57-74. doi:10.1353/foc.2016.0012.

\section{Published Version}

doi:10.1353/foc.2016.0012

\section{Permanent link}

http://nrs.harvard.edu/urn-3:HUL.InstRepos:34785394

\section{Terms of Use}

This article was downloaded from Harvard University's DASH repository, and is made available under the terms and conditions applicable to Open Access Policy Articles, as set forth at http:// nrs.harvard.edu/urn-3:HUL.InstRepos:dash.current.terms-of-use\#OAP

\section{Share Your Story}

The Harvard community has made this article openly available.

Please share how this access benefits you. Submit a story.

\section{Accessibility}




\section{Reading and Language in the Early Grades}

\section{Catherine E. Snow and Timothy J. Matthews}

\section{Summary}

How does literacy develop in children's early years, and what programs or practices promote adequate literacy for all children? These are the questions Catherine Snow and Timothy Matthews tackle in this article.

Fundamental literacy skills can be grouped into two categories, Snow and Matthews write. The first category is constrained skills, which are readily teachable because they're finite: for example, the 26 letters of the alphabet, or a set of 20 to 30 common spelling rules. These skills have a ceiling; young children can and do achieve perfect performance.

As they grow older, though, children need to understand words rarely encountered in spoken language and to integrate new information they encounter with relevant background information. Vocabulary and background knowledge are examples of unconstrained skillslarge domains of knowledge acquired gradually through experience. Unconstrained skills are particularly important for children's long-term literacy success (that is, success in outcomes measured after third grade). Compared to constrained skills, they're also more strongly predicted by children's social class or their parents' education, and more difficult to teach in the classroom. And because of their open-ended nature, unconstrained skills are also much harder to test for. Snow and Matthews write that a drop in literacy scores we see as US children move from elementary to middle school suggests that our schools may be focusing too much on constrained skills - and too little on unconstrained ones-in the early grades.

The authors review promising programs and practices for enhancing both constrained and unconstrained skills, ranging from comprehensive school-improvement programs to efforts to improve curricula and teachers' professional development-although they note that vast differences in programs' scope, cost, targets, and theories of change make comparing them difficult. Another challenge is that it's hard to maintain quality and consistency when implementing complex programs over time. Snow and Matthews suggest that to improve young children's success with literacy, it might be better to introduce and evaluate promising practices that can be mixed and matched, rather than complex programs that are implemented as a package.

www.futureofchildren.org

Catherine Snow is the Patricia Albjerg Graham Professor of Education and Timothy Matthews is an EdD candidate at the Harvard Graduate School of Education.

Fred Morrison of the University of Michigan reviewed and critiqued a draft of this article. 


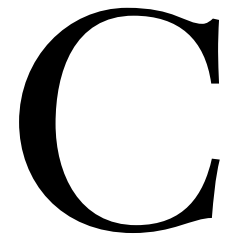
hildren who don't develop age-appropriate literacy skills by the end of third grade are at high risk of school failure. Longitudinal research conducted over almost 40 years has confirmed that differences between high school dropouts and graduates can be identified as early as third grade. ${ }^{1}$ Thus we need to understand how literacy develops in the early years and what programs or practices promote adequate literacy for all children. In this article, we summarize the key components of literacy, characterize how US children are performing in literacy, identify some features of excellent literacy instruction, and discuss why early literacy instruction isn't universally more effective.

\section{What Is Literacy in the Early Grades?}

By the end of third grade, children in the English-speaking world are expected to have acquired the foundational literacy skills. Literacy, though, is a complex domain with many components, so it's important to clarify what those foundational skills are, how they relate to one another, and how or whether they predict longer-term literacy success (see table 1).

One set of skills consists of those that parents and preschool teachers value and actively promote: reciting the alphabet, recognizing and writing letters, writing one's own name, reading environmental print (signs and labels), and knowing how to hold a book upright and turn the pages. Another important skill is promoted less consciously, by exposing children to rhymes and phonological play: the recognition that words are made up of smaller units of sound, which can be manipulated independently, as in the changes rung on "I Like to Eat Apples and Bananas" in the popular children's song (I like to eat eeples and beeneenees), or versions of familiar phrases with one sound replaced by another (Junkin Jonuts, Bunkin Bonuts, Funkin Fonuts). Recognizing that words are made up of sounds (called phonemes) is a key early literacy achievement, because children must learn to map those phonemes to letters or letter sequences (called graphemes) to read unfamiliar words (decode). Teachers in the first years of school focus on helping children learn and apply the basic principles for mapping sounds into print and vice versa. If the teaching is successful, children can read even unfamiliar words accurately and, after considerable practice, effortlessly. In English, because of its complex set of mapping principles from sound to spelling and vice versa, children may take two to three years to master this task (and to learn the one or two hundred common sight words that must be memorized because they deviate from decodable spelling patterns).

This relatively long list of fundamental literacy skills, however, is far from comprehensive. So far we've discussed constrained skills, meaning those that are directly teachable because the domain is finite: 26 letters, 44 phonemes, a set of 20 to 30 commonly taught spelling rules (for example, drop a final silent $e$ before -ing), and 100-plus sight words. Constrained skills have a ceiling; the learner can achieve perfect performance. Within the domain of constrained skills, we see clear predictive relationships-for example, phonological awareness predicts the ability to decode and spell-that confirm the importance of mastery. But the time and the attention required for mastery are finite. 
Table 1. Skills Children Acquire Starting in Preschool That Affect Literacy

\begin{tabular}{llll}
\hline \multicolumn{1}{c}{ Constrained skills } & \multicolumn{1}{c}{$\begin{array}{c}\text { Unconstrained skills } \\
\text { Print-related }\end{array}$} & \multicolumn{1}{c}{ Sound-related } & \multicolumn{1}{c}{ Lnowledge } \\
\hline $\begin{array}{l}\text { Letter recognition } \\
\text { Writing one's }\end{array}$ & Reciting the alphabet & Vocabulary & Topic-specific knowledge \\
own name & Rhyming & Grammar & $\begin{array}{l}\text { (science, geography, social } \\
\text { structures) }\end{array}$ \\
$\begin{array}{l}\text { Reading environmental } \\
\text { print (signs, labels) } \\
\text { Book handling }\end{array}$ & $\begin{array}{l}\text { Segmenting initial } \\
\text { phonemes (say frog } \\
\text { without the fff) }\end{array}$ & Story structure & Information seeking \\
& Invented spelling & Telling narratives & Requesting explanations \\
& & Giving descriptions &
\end{tabular}

Once children master the constrained skills, they can accurately and automatically read most words, and thus successfully comprehend texts written at second- or third-grade level, because the words used and the topics covered are familiar to them. Beyond third grade, though, successful comprehension requires children to understand words rarely encountered in spoken language and to integrate new information encountered in the text with relevant background information. Vocabulary and background knowledge are unconstrained skills-large domains acquired gradually through varied experience, rather than through focused instruction. These domains become increasingly crucial to comprehension as the texts children encounter range more widely in topic and language complexity ${ }^{2}$.

Unconstrained skills are particularly important in predicting long-term literacy outcomes (that is, outcomes measured after third grade). They're also more strongly predicted by children's social class or parental education, and more difficult to influence through classroom instruction, than constrained skills are. Unconstrained skills include language skills (vocabulary, grammar, and discourse skills) and general knowledge of the world. As early as second grade, children with larger vocabularies read words more accurately, presumably because knowing a word supports correct pronunciation while decoding. ${ }^{3}$ Even stronger relationships emerge in later grades, when students read more complex texts. Knowing what the words mean and having some background knowledge relevant to the text become the strongest predictors of successful comprehension among students who have acquired basic decoding skills.

Researchers and educators widely acknowledge that language skills and world knowledge are important for success with literacy. Yet many prekindergarten through third-grade classrooms, particularly those serving low-income children, still focus on constrained skills, which are easy to teach and easy to test. Ensuring that teachers pay appropriate attention to unconstrained skills in early childhood and primary classrooms is a serious challenge.

\section{Performance in Literacy}

In international comparisons from 2011, US fourth-graders performed fairly well on literacy assessments - higher than the international average of 53 education 
systems participating in the Progress in International Reading Literacy Study (PIRLS), and among the top 13 of those systems. ${ }^{4}$

Though the international results are encouraging, the 2015 National Assessment of Educational Progress (NAEP), conducted in the United States alone, paints a less rosy picture..$^{5}$ Only 36 percent of fourth-graders scored at or above proficient, and children scoring at the 50th percentile achieved a score of 225 on a 500 -point scale. The overall average of 36 percent proficient masks disparities associated with race (only 18 percent of blacks and 21 percent of Hispanics or Native Americans scored proficient), gender (only 33 percent of males), and location (only 32 percent of urban students). These percentages were unchanged from 2013.

How do we reconcile US students' satisfactory performance on the PIRLS with the disappointing NAEP results? First, we should note that proficient is a high standard. The National Assessment Governing Board, which oversees the NAEP Reading Framework, defines proficiency as the ability to infer characters' motivation, explain a theme, identify elements of an author's craft, find evidence to support an argument, distinguish fact from opinion, and draw conclusions. Basic-level reading in fourth grade consists of the ability to find information, make simple inferences, identify mood, find topic sentences, identify the author's explicitly stated purpose, and make simple inferences. Thus children who perform at the basic level are reading with some level of comprehension. Furthermore, in 2002 the NAEP tested a national sample of fourth-graders on their oral reading fluency and accuracy. Three-quarters read a fourthgrade level text with 95 percent accuracy (no more than 5 percent of words missed or mispronounced), and 65 percent read more than 105 words per minute, the rate at which basic comprehension was achieved.

The NAEP fluency study, then, suggests that US schools are doing a fairly good job of teaching most students the basic skills of reading words accurately and relatively quickly. In contrast, most third-graders tested in Nigeria (81 to 88 percent) and Mozambique (63 to 67 percent) couldn't read a single word accurately on a test of oral reading fluency. These are children who have received schooling but evidently no effective instruction in literacy. ${ }^{6}$

Beginning in third grade, students across the United States are tested for progress on literacy using a patchwork of state and multistate assessments; the skills tested vary from assessment to assessment. It once seemed likely that the Partnership for Assessment of Readiness for College and Careers (PARCC) and Smarter Balanced tests, which were developed to align with the Common Core State Standards (CCSS), would lead to more standardization across states and a greater focus on making comprehension assessments more challenging. But intensifying public skepticism about the Common Core standards themselves, coupled with rejection or adaptation of the accompanying assessments, suggests that considerable variability from state to state will continue. Perhaps because of the lack of statelevel accountability before third grade, comparatively fewer assessments are used to monitor the progress of preschool and early elementary students. 
One nationally normed test for $\mathrm{K}-3$ students is DIBELS Next, developed by Ruth Kaminski and Roland Good at the University of Oregon Center on Teaching and Learning and intended to be given at the beginning, middle, and end of a student's school year. ${ }^{7}$ In kindergarten, children are assessed on basic tasks such as accuracy and speed of naming letters, and identifying the first sound in a word. As children reach second and third grade, they are tested for oral reading fluency. Students who take the test receive a percentile rank that educators can compare to a national sample of children. DIBELS Next is useful and convenient, and it has undeniably led educators to pay more attention to children's ability to read quickly and without undue struggles to decode. But it is more sensitive to constrained than to unconstrained skills.

\section{Beyond DIBELS Next, school}

psychologists, reading specialists, and teachers certified in special education use a variety of assessments to identify struggling readers. Teachers, assistant teachers, and aides may also use their own informal assessments to gauge their children's progress.

\section{Our schools may be focusing too much on constrained skills-and too little on unconstrained ones - in the early grades.}

Are US schools doing a good job of balancing their success in producing accurate and fluent readers with attention to producing linguistically sophisticated students who will have the background knowledge needed to comprehend middlegrades texts? The drop in literacy scores by eighth grade, both on the NAEP and in international comparisons, suggests that our schools may be focusing too much on constrained skills_-and too little on unconstrained ones-in the early grades.

\section{Reading First}

Word reading accuracy and fluency was a specific goal of Reading First, a $\$ 1$ billion per year federal effort launched in 2002 to align reading instruction in eligible US schools - those that served a high percentage of low-income students - with what was understood to be scientifically based reading instruction. The theory behind Reading First was that poor reading outcomes could be explained by weaknesses in young students' decoding and fluency. The National Reading Panel (NRP)—a 14-member committee formed in 1997 in response to a Congressional request that the National Institute of Child Health and Human Development and the US Department of Education identify an expert panel to determine how children should be taught to read-issued its recommendations in 2000. Its members-including educators, school administrators, and researchers-concluded from a review of rigorous research studies that there was strong support for five instructional practices: teaching phonological awareness, phonics, fluency, vocabulary, and comprehension strategies. ${ }^{8}$ Districts that received Reading First grants were required to adopt one of an approved list of reading programs, all of which were judged to put sufficient emphasis on structured phonics instruction, and to commit at least 90 minutes a day to literacy instruction in first through third grade. 
Abt Associates and MDRC, two research organizations that are often asked to review the impacts of national education and social policy initiatives, evaluated Reading First in 2008, comparing schools that received the funding to similar schools that hadn't. ${ }^{9}$ Reading First teachers spent significantly more time teaching phonemic awareness, phonics, vocabulary, fluency, and comprehension in first and second grade. Reading First schools offered teachers more professional development focused on the five instructional practices, and offered more support for struggling readers. These large changes in practice translated into small improvements in first-grade decoding skills (for readers familiar with statistical analysis, less than one-fifth of a standard deviation, an effect considered small but educationally relevant), but no other impacts were seen. Strikingly, reading comprehension didn't improve at all.

These Reading First findings confirm two conclusions that have emerged from multiple studies. First, it's easier to improve classroom practices than the skills of children in those classrooms. Second, constrained skills are easier to improve than unconstrained skills.

Interventions (for example, new curricula or professional development) quite frequently show effects on what teachers do, how much time they spend on recommended activities, how they organize their classrooms, and other features of their practice. ${ }^{10}$ These improvements in classroom practice may not be reflected in children's skills for several reasons: the improvements may be insufficiently robust or sustained; it may take a few years for teachers to get really good at them; or the students may be in the classroom too infrequently to benefit from the improved teaching. In one study of a professional development intervention in prekindergarten classrooms, the children who were consistently present in the classroom showed positive effects, but 66 percent of the group were absent for more than 10 percent of the school year, and there were no significant effects for the group of children as a whole. ${ }^{11}$

Constrained skills are easier to improve for a number of reasons. They constitute well-defined goals, and we have proven approaches to teaching and to assessing them. Many techniques help four- to fiveyear-olds develop phoneme awareness. For example, teachers can ask such questions as:

- This is Bear Bertie. What color begins with same sound as Bear Bertie?

- This is Ferret Freddie. What would his name be without the fff?

- Which sounds more like log, cat or dog? Can you think other words that rhyme with $\log$ ?

These brief phoneme awareness lessons are easy to carry out. The techniques for teaching new vocabulary are much more complicated: selecting the right words to teach, ensuring that children hear those words in rich semantic contexts, giving the words child-friendly definitions, exposing the children to the words many times, and creating contexts where the children can use the new words. Teachers need much more curricular support to do a good job when it comes to unconstrained domains like vocabulary. Furthermore, once children have mastered a constrained domain, they reliably display that skill on any test of the domain. In contrast, a child who has learned all the words in an effective vocabulary curriculum 
is unlikely to encounter any of them on a standardized vocabulary test.

\section{Classroom Challenges}

Early childhood and primary classrooms typically comprise children at many different levels of language and literacy development. These differences are larger in socioeconomically diverse classrooms, because we see substantial social class differences in literacy-related skills even before most children enter preschool. ${ }^{12}$ These social class differences encompass both constrained and unconstrained skills, but the differences in unconstrained skills are greater and more persistent. Thus a comprehensive effort to promote good literacy outcomes for all children must incorporate not only preschool programs but also programs designed for children from birth to three years old and their families.

\section{Promising Programs and Practices}

Efforts to improve children's literacy vary in many ways. Reading First, for example, used financial incentives for school districts that implemented the reading methods it endorsed to influence the mix of practices in classrooms, while Success for All is a comprehensive school-improvement program with a strong emphasis in its literacy component on phonological awareness and structured phonics. Other programs rely on curriculum or professional development. Some are designed for all students, whereas others target students who have trouble learning to read. Still others target very specific skills (notably, phonological awareness or vocabulary), on the theory that weaknesses in those skills constitute bottlenecks in literacy development. Given the variety we see in literacy programs' scope, cost, targets, and theories of change, comparing them is difficult.

Reading First promoted a set of practices that small experimental studies had identified as effective. Unfortunately, those practices didn't add up to a comprehensive literacy program, in part because they were too often limited to the constrained skills reflected in third-grade assessments. Furthermore, expanding classroom time for these practices squeezed out activitiessuch as reading books aloud, science instruction, field trips, and discussion-based learning - that have been associated with the development of unconstrained skills. So, although adding specific proven practices into a comprehensive literacy program might well have been productive, substituting an exclusive focus on those practices for a well-rounded program was not. When we evaluate literacy interventions, we need to understand the larger context in which they're implemented. We turn now to consider large-scale efforts to improve outcomes for all participating students.

\section{Success for All}

Success for All, surprisingly, wasn't one of the programs approved for funding under Reading First. Thus despite a record of successfully supporting literacy development in schools serving high-risk students, Success for All shrank significantly when Reading First was in its ascendancy. Success for All is also relentlessly empirical; if a review of research suggests that a practice (for example, grouping students by reading level or collaborative learning) is helpful, that practice is introduced into the program, which may thus best be characterized as a mosaic of practices rather than an approach driven by a particular theory. That mosaic 
of practices includes systematic approaches to teaching reading to homogeneous groups, regular assessment and regrouping, and tutoring children who fall behind. Because Success for All provides its own recommended curricular resources, it offers greater scope for integrating newly identified, effective practices instead of replacing traditional approaches with new ones.

Robert Slavin, the Johns Hopkins professor who launched Success for All, collaborated with other researchers in a rigorous experimental study to evaluate the program's effectiveness in the primary grades. ${ }^{13}$ Success for All students scored higher than the study's control group on three domains of literacy: decoding unfamiliar (nonsense) words, as well as decoding and comprehension. These effects (which ranged from 0.2 to 0.3 of a standard deviation) were equivalent to about a year's worth of learning, but they emerged only after children had been in Success for All for three years, presumably because it takes time for such a program to become well established and be carried out properly in any school, and because students benefit from lengthier exposure to the integrated and systematic curriculum.

A recurrent theme in evaluations of Success for All, though, is that the impacts were greatest for measures of phonological awareness but more modest for decoding and comprehension. Harvard researchers Lowry Hemphill and Terry Tivnan compared Success for All to three other literacy approaches that were less focused on phonics and were being tried in a single school district: Building Essential Literacy, Developing Literacy First, and Literacy Collaborative. Success for All scored better than the others on decoding but below the other programs on promoting vocabulary, writing, or comprehension skills. ${ }^{14}$

Success for All's impact is also affected by how strictly educators follow its guidelines. In a series of interviews with teachers and observations in schools implementing Success for All, Johns Hopkins University researchers Amanda Datnow (now of the University of California at San Diego) and Marisa Castellano (now of the University of Illinois) found that educators often modified the program, despite the fact that the designers stressed that implementing it with fidelity was important for the program's success. However, teachers' personal level of support for Success for All didn't seem to affect how likely they were to carry out its practices with fidelity; rather, educators who took part in the study complained that the program constrained their creativity and autonomy. ${ }^{15}$

\section{Publisher-Developed Curricula}

Reading curricula developed by textbook publishers are widely used in districts and schools across the United States. Accordingly, they substantially influence teachers' day-to-day instruction and students' learning. However, we have only limited evidence that such curricula are effective, or that picking one curriculum over another matters much for elementary children's literacy skills. For example, one district-level study of Pearson's kindergarten to sixth-grade curriculum, Reading Street, found no statistically significant improvements in third-grade reading outcomes compared to the curriculum used previously. In the same study, teachers reported that they were generally satisfied with the curriculum. ${ }^{16}$ 
Changing children's trajectories as they move from kindergarten through fourth grade often requires additional support for children who are struggling when they enter elementary school.

In the absence of curricular impacts, the role of the classroom environment in which students are immersed is paramount. One of the authors of this article, Catherine Snow, along with her colleagues Patton Tabors and David Dickinson, developed a road map for the kinds of interactions in early childhoodwith parents, caregivers, or teachers-that prepare the ground for children to progress as readers. ${ }^{17}$ Children who come from homes with few activities that fertilize the ground for reading success can be helped significantly by school environments where such experiences abound. Changing children's trajectories as they move from kindergarten through fourth grade often requires that we invest in additional support for children who are struggling when they enter elementary school. Some researchers who focus on implementing effective literacy instruction at the classroom level argue that we need assessments sufficient to paint a picture of students' individual, group, and aggregate needs; this would allow core instruction and targeted supports to be tailored for an individual classroom's or school's needs. ${ }^{18}$ Moreover, writes Harvard researcher Paola Uccelli, although a generalized understanding of the needs of, for example, English language learners might help guide instruction, it's also "necessary to remember that each child is unique and reflects diverse experiences not always easily classifiable as those of one discrete cultural group. Children vary enormously even within the same cultural group." 19

\section{Efforts That Focus on Constrained Skills}

Fifteen years ago, the NRP summarized 52 studies of phonemic awareness interventions published before 2000 and found generally large positive effects (ranging in size from half of a standard deviation to more than two standard deviations-students typically show growth of about a quarter of a standard deviation in one year). ${ }^{20}$ Since 2002, dozens more studies have shown that phonemic awareness strongly predicts successful early literacy learning, a finding reinforced by a 2008 review of early literacy research carried out by the National Early Literacy Panel..$^{21}$

Similarly, the NRP reported positive effects from interventions that offered structured phonics instruction—systematic instruction about the links between letters and sounds. However, many of the children in the studies that the panel examined were selected for intervention because they were having trouble learning to read from the regular classroom instruction that worked well for many of their classmates. Thus the strong emphasis on phonics instruction that emerged from the NRP and its elevation into policy through Reading First might be compared to prescribing a gluten-free diet for everyone because it helps people with celiac disease. It's clear, of course, that word-reading skills strongly predict ultimate reading outcomes-comprehension requires reading words, after all. But it’s equally 
clear that not all children need structured phonics instruction. The question is whether all children benefit from it or whether any suffer negative consequences. Since Harvard researcher Jeanne Chall's pioneering work, published in the early 1980s, scholars have hypothesized that children at risk of poor reading outcomes (whether because of reading disabilities, low family support for literacy, or other reasons) benefit most from well-sequenced phonics instruction. ${ }^{22}$ No systematic large-scale tests of this hypothesis have been carried out. But Carol Connor, a reading researcher then at Florida State University, created an algorithm to match teaching emphasis to first graders' profiles of skills. In a carefully conducted experimental study, she found that some first-graders benefited from instructional activities with considerable teacher-led focus on the code (that is, phonological awareness and phonics), whereas others benefited more from student-led instructional activities that focused on meaning. ${ }^{23}$ In other words, a focus on phonics helped children who needed it, but some children benefited more from self-selected reading or writing activities.

In 2013, a group of researchers at Columbia University's Teachers College undertook a cost-benefit analysis of seven early literacy interventions, all designed primarily for students struggling to reach gradelevel standards. ${ }^{24}$ The programs varied enormously in their cost per student (from $\$ 27$ to $\$ 10,108)$, and the delivery method ranged from structured whole-class lessons to supplementary tutoring and computermediated support. All of the programs focused on alphabetics (which encompasses phonemic and phonological awareness, letter identification, print awareness, and decoding/spelling), and all produced improvements in alphabetic skills (with effect sizes ranging from one-fifth to fourfifths of a standard deviation). A couple of the programs also showed effects on fluency, and one (Sound Partners, an 18-week-long program for struggling kindergartners) improved reading comprehension, a skill that for kindergartners is largely determined by word reading. There was no relationship between cost of a program and size of the improvements it produced.

One of the programs included in this cost-benefit comparison is called Reading Recovery. It follows a constructivist approach to identifying struggling readers and giving the bottom 15 percent of students in each classroom additional support from a specially trained literacy teacher, starting in first grade (that is, after the first year of widespread schooling). This approach was developed by New Zealand educator Marie Clay, and has been widely implemented in the United States by teachers trained at The Ohio State University and Lesley University. The What Works Clearinghouse-an initiative of the Institute of Education Sciences at the US Department of Education dedicated to promulgating best practices gleaned from reviews of high-quality research-lists it as an effective program.

From the 1970s until the present, New Zealand's early literacy strategy has revolved around Reading Recovery, which was made into national policy by the Ministry of Education. William Tunmer, now at the University of Canterbury, and James Chapman of Massey University and their colleagues detail the story in a recently released report arguing that New Zealand's national literacy strategy has failed. Their critique focuses on the Reading Recovery protocol's resistance to evidence-based 
modifications (for example, supplementing the instruction with some attention to phonics), and on the inefficiency of using the program with the poorest readers in every classroom. Tunmer and Chapman point out that in schools serving middle-class students, the worst readers read better than the best students in schools serving less privileged children, most of whom get no special help. The policy thus exacerbates differences within the country's racial and ethnic subgroups when children enter school. ${ }^{25}$ Although Reading Recovery is used to some degree in Australia, Canada, the United Kingdom, and the United States, nowhere but in New Zealand has it been used so pervasively on a national basis.

The robust finding that targeted interventions can influence phonological awareness, word reading, and other alphabetic skills shows how important it is to make a distinction between constrained and unconstrained skills. ${ }^{26}$ Are any programs effective at helping children develop unconstrained skills?

\section{Efforts That Focus on Unconstrained Skills}

Vocabulary is the most widely studied unconstrained skill. A meta-analysis of programs designed to promote vocabulary learning in four- to eight-year-old children (from prekindergarten through third grade) showed that these programs had sizable effects (almost nine-tenths of a standard deviation). However, the programs didn't eliminate social class differences in vocabulary; in fact, better-off children were more likely to benefit than were poorer children. ${ }^{27}$ And, as is often the case in vocabulary evaluations, assessments designed by researchers showed larger gains than did standardized assessments. This recurrent finding reflects a challenge of teaching and testing unconstrained skills: the problem space (all the vocabulary in a language) is much larger than the training space (the 30 to 200 words actually taught), and there may be no way for children to generalize from trained to untrained items.

University of Michigan researcher Susan Neuman developed the World of Words, a vocabulary intervention for children in prekindergarten, precisely to promote generalization. ${ }^{28}$ World of Words focuses on teaching words that fit together into conceptual structures; for example, words related to insects may be taught in science units about insects that also teach about the characteristics of insects that distinguish them from other organisms, and so on. When Head Start classrooms were randomly assigned to use the World of Words curriculum or not, children in classrooms that used the program learned more words and, to some extent, closed the vocabulary gap with better-off children. They were more likely to produce generalizations about the categories they learned and to make inductive inferences about novel words. Though it included no standardized assessments, this study nonetheless suggests that embedding the unconstrained domain of vocabulary inside another unconstrained domain, world knowledge, promotes learning of both.

World of Words' success may result from well-designed curricular materials that supported productive classroom talk. Researchers Christina Weiland of the University of Michigan and Hirokazu Yoshikawa of New York University showed in a 2013 study that when a public prekindergarten program coached teachers 
in how to use a rich language and literacy curriculum called Opening the World of Learning, children's vocabulary (as well as emergent literacy, numeracy, and selfregulation skills) improved compared with children who were just shy of the cutoff age to enroll. ${ }^{29}$ Because the children who missed the enrollment cutoff were exposed to a variety of other experiences, ranging from home care to alternate prekindergarten programs, we don't know precisely which aspects of Opening the World of Learning-the curriculum itself, children's exposure to qualified teachers, or their participation in structured daily activities with highly qualified teacherswere responsible for the gains.

A review of the effectiveness of early childhood curricula based on a What Works Clearinghouse report concluded that only one of 13 curricula-the Literacy Express Comprehensive Preschool Curriculumhad strong evidence of positive effects on oral language. Two others had some evidence of positive effects, one had some evidence of negative effects, and nine showed no effects. ${ }^{30}$ An analysis of the content covered by Literacy Express and Opening the World of Learning might tell us more about the features of successful, well-designed early childhood language curricula.

One of the very few instructional practices shown to improve young children's language skills without introducing specific curricula or a focus on vocabulary is called Storytelling and Story Acting, invented by a fabled kindergarten teacher at the University of Chicago Lab School, Vivian Gussin Paley. ${ }^{31}$ In this technique, children are encouraged to dictate stories to the teacher, then to select classmates to help act out the stories while the teacher reads them aloud. After Paley described the practice, other early childhood educators adopted it based on her vivid depictions. Ageliki Nicolopoulou of Lehigh University and her colleagues decided to evaluate it by introducing it into six Head Start classrooms serving three- and fouryear-olds and comparing the children with those in seven other classrooms. ${ }^{32}$ Children who participated in Storytelling and Story Acting for one school year showed greater gains in storytelling and story comprehension, vocabulary, early literacy skills, and ability to pretend. Children who participated in telling and acting the most stories showed the greatest gains. Storytelling and Story Acting is powerful because it engages children and helps them develop language and literacy skills (as well as self-regulation and peer cooperation) within the normal pattern of preschool classrooms. Story dictation can take place at an activity center, and story acting (which takes only a few minutes) at circle time or pre-lunch meeting time. Storytelling and Story Acting requires no special curricular materials and is essentially free once teachers have received some basic professional development. (It was also implemented in the prekindergarten classrooms studied by Weiland and Yoshikawa.)
A good curriculum's
effect on children may be produced not by the curriculum itself but by the teacher talk that results. 


\section{Language Environments in Early Childhood and Primary Classrooms}

Curricular support for teachers is a frequently noted feature of good early childhood programs, and a rich and logically sequenced curriculum is the backbone of well-structured primary literacy instruction. Although developing and promoting good curricula clearly offers valuable support to teachers, the effect on children may be produced not by the curriculum itself but by the teacher talk that results. Considerable evidence suggests that quality of teachers' talk influences students' opportunities to learnin particular, to learn the unconstrained language and content skills relevant to literacy. Children whose preschool teachers use more sophisticated vocabulary, engage them more actively in talk about books, and use more complex syntax themselves show larger vocabularies, more complex grammar, and better reading skills even as late as fourth grade. ${ }^{33}$ All the studies showing these relationships are correlational, and thus we don't have a strong basis for inferring causality. Nonetheless, the pattern is robust, and we should invent ways to promote more sophisticated teacher talk if we wish to test its effects on child outcomes.

High-quality teaching fosters a highquality learning environment for children in prekindergarten and the early grades. ${ }^{34}$ That learning environment, particularly in prekindergarten, relies on four components: explicit instruction; warmth and sensitivity to the needs of students; consistent feedback to and interaction with students; and verbal stimulation. These conclusions about early childhood-learning environments parallel those found in various studies of K-12 classrooms. $^{35}$
However, we have less consistent evidence for the role of professional development and coaching programs in producing higher-quality academic outcomes for students, regardless of which curriculum or intervention is being implemented. Johns Hopkins's Slavin and colleagues found that interventions targeting teachers' own classroom practices were more successful than those that aimed to improve students' reading skills in the early grades. ${ }^{36}$ Teachers need information about students' skills and the expected progressions of skill, as well as support for trying new ways of teaching and interacting with students. ${ }^{37}$ Often the best support involves new curricular materials paired with guidance in using them. In one study, the University of Michigan's Neuman and Linda Cunningham of Brown University found that a combination of professional development and coaching fostered a more positive classroom environment in preschool. ${ }^{38}$ However, they write, we don't know much about whether it's feasible to bring such efforts to scale-especially when we think about the diversity of early childhood-education programs.

\section{Fostering Reading in Pediatric Care Settings}

Reach Out and Read is an intervention in which primary-care pediatricians talk with parents about why reading is important and share strategies for reading with their child; families, meanwhile, receive a new book to take home at every regular pediatric check-up, starting when the child is six months of age. A review of 11 studies of Reach Out and Read concluded that the intervention's quality was mixed. ${ }^{39}$ Across the studies, Reach Out and Read's outcome was often more frequent book reading, rather than children's development or 
specific language skills. One study of more general efforts to promote book reading through pediatric care suggests doing so can improve receptive and expressive vocabulary in older toddlers (from 18 to 25 months) ${ }^{40}$ Showing parents brief videos of responsive parent-child interactions in pediatricians' offices - in an effort to enhance the effects of giving families a book-has also shown positive effects, both on children's language and on attention and imitative play. ${ }^{41}$ But we need more research to understand the best way to use pediatric visits to promote more persistent gains in children's literacy skills.

\section{Conclusions}

It's hard to neatly summarize what influences early literacy, because the target domain must be very broadly conceived and the sources of influence are many. The numerous skills listed in this article all constitute components of or precursors to success in school literacy tasks. These include constrained skills (such as phonemic awareness and letter knowledge) that are appropriately identified as outcomes at ages four to six, and unconstrained skills (such as vocabulary and world knowledge) that are harder to test in young children but are ultimately more relevant to long-term literacy success. Instructional and intervention programs in early childhood through third grade show greater success in influencing constrained skills, or directly targeted subdomains within the unconstrained skills (for example, the words actually taught in a vocabulary curriculum). But evidence of broader and longer-term impacts on reading comprehension is scarce.

The varying quality and consistency with which classroom instructional programs are implemented in prekindergarten through third grade constitute a huge challenge in evaluating these programs' impacts. Whether because well-designed programs are inherently complicated, because professional development and coaching support is insufficient, because of teacher burnout, or because of teacher turnover and lack of mechanisms for effective induction of new personnel, maintaining successful implementation over long periods is challenging. Nonetheless, specific practices within the programs that show initial success may well be sustainable and valuable in promoting the desired impacts; rethinking comprehensive programs as collections of proven practices that could be mixed and matched, rather than implemented as a package, might be a route to generally more effective literacy instruction.

We also see strong hints in the research that certain kinds of curricular content, supplemented with guidance to teachers about implementation, can strongly support better early childhood outcomes. Curriculum in early childhood has generally been downplayed, seen as too academic and insufficiently responsive to children's interests and need to play. As a result, early childhood educators are left either working overtime to come up with curricular resources or seizing upon relatively banal topics (pumpkins in October, turkeys in November, snowflakes in December) that fail to expand children's vocabularies or world knowledge very much. Simply focusing on practices in professional development for early childhood educators (talk more, ask more open-ended questions, select interesting words from read-aloud texts to talk about) is demonstrably less effective than providing sets of books related 
to a theme for reading aloud, identifying the words to be talked about and the questions to be asked, and providing guidance for center activities (act-outs, art, sandbox, or block corner) that echo and thus reinforce the theme of the books. Directly comparing the impacts of improved curricular resources with modest investment in professional development to much more extensive general-purpose professional development would provide some guidance about the most efficient route to improved outcomes.

It's worth noting, though, that many programs to improve literacy through interventions in early childhood did show effects on aspects of classroom functioning, even in the absence of impacts on children. This juxtaposition suggests how difficult it is to influence literacy outcomes through formal education alone. Literacy skills are, ultimately, the product of everything a child has learned about language and about content expressed through language. The accumulated advantages that accrue to children who've been exposed to rich language and content from birth can't easily be matched in a few hours a day of instruction, however well-designed and implemented. 


\section{ENDNOTES}

1. Dee Norman Lloyd, "Prediction of School Failure from Third-Grade Data," Educational and Psychological Measurement 38 (1978): 1193-1200, doi: 10.1177/001316447803800442; Donald J. Hernandez, Double Jeopardy: How Third-Grade Reading Skills and Poverty Influence High School Graduation (Baltimore, MD: Annie E. Casey Foundation, 2012).

2. Susan R. Goldman and Catherine E. Snow, "Adolescent Literacy: Development and Instruction," in Handbook on Reading, ed. Alexander Pollatsek and Rebecca Treiman (New York: Oxford University Press, 2015), 463-78, doi: 10.1093/oxfordhb/9780199324576.013.25.

3. Catherine E. Snow et al., "SHELL: Oral Language and Early Literacy Skills in Kindergarten and First Grade Children," Journal of Research in Childhood Education 10 (1995): 37-48, doi: $10.1080 / 02568549509594686$.

4. "Progress in International Reading Literacy Study (PIRLS): PIRLS 2011 Results," National Center for Education Statistics, accessed January 31, 2016, https:/nces.ed.gov/surveys/pirls/pirls2011.asp.

5. “2015 Mathematics and Reading Assessments,” The Nation’s Report Card, accessed January 31, 2016, http://www.nationsreportcard.gov/reading_math_2015/\#reading/scores?grade=4

6. “Early Grade Reading,” USAID, accessed January 31, 2016, https://www.eddataglobal.org/reading/.

7. Elizabeth N. Dewey, Ruth A. Kaminski, and Roland H. Good, III, DIBELS Next ${ }^{\circledR}$ National Norms 2012-2013 (Technical Report No. 17) (Eugene, OR: Dynamic Measurement Group, 2014).

8. "Teaching Children to Read: An Evidence-Based Assessment of the Scientific Research Literature on Reading and its Implications for Reading Instruction," National Reading Panel (2002), http://www.nichd. nih.gov/publications/pubs/nrp/documents/report.pdf.

9. “Reading First Impact Study, Final Report,” Abt Associates (2008), http://www.abtassociates.com/reports/ Reading_First_Final_Report_11-06-08.pdf.

10. See, for example, Diana Leyva et al., "Teacher-Child Interactions in Chile and Their Associations with Prekindergarten Outcomes," Child Development 86 (2015): 781-99, doi: 10.1111/cdev.12342; Hirokazu Yoshikawa et al., "Experimental Impacts of a Teacher Professional Development Program in Chile on Preschool Classroom Quality and Child Outcomes," Developmental Psychology 51 (2015): 309-22, doi: 10.1037/a0038785.

11. Mary Catherine Arbour et al., "Experimental Impacts of a Preschool Intervention in Chile on Children's Language Outcomes: Moderation by Student Absenteeism," Journal of Research on Educational Effectiveness (2016), doi: 10.1080/19345747.2015.1109013.

12. David K. Dickinson, Allyssa McCabe, and Marilyn J. Essex, "A Window of Opportunity We Must Open to All: The Case for Preschool with High-Quality Support for Language and Literacy," in Handbook of Early Literacy Research, vol. 2, ed. David K. Dickinson and Susan B. Neuman (New York: Guilford Press, 2006), 11-28; Betty Hart and Todd R. Risley, Meaningful Differences in the Everyday Experience of Young American Children (Baltimore: Brookes Publishing, 1995); Dale Walker et al., "Prediction of School Outcomes Based on Early Language Production and Socioeconomic Factors," Child Development 65 (1994): 606-21, doi: 10.1111/j.1467-8624.1994.tb00771.x.

13. Geoffrey D. Borman et al., "Final Reading Outcomes of the National Randomized Field Trial of Success for All," American Educational Research Journal 44 (2007): 701-31, doi: 10.3102/0002831207306743.

14. Lowry Hemphill and Terrence Tivnan, "The Importance of Early Vocabulary for Literacy Achievement in High-Poverty Schools," Journal of Education for Students Placed at Risk 13 (2008): 426-51, doi: 10.1080/10824660802427710. 
15. Amanda Datnow and Marisa Castellano, "Teachers' Responses to Success for All: How Beliefs, Experiences, and Adaptations Shape Implementation," American Educational Research Journal 37 (2000): 775-99.

16. Jamie Ladnier-Hicks, Rose M. McNeese, and James T. Johnson, "Third Grade Reading Performance and Teacher Perceptions of the Scott Foresman Reading Street Program in Title I Schools in South Mobile County," Journal of Curriculum and Instruction 4 (2010): 51-70.

17. Patton O. Tabors, Catherine E. Snow, and David K. Dickinson, "Homes and Schools Together: Supporting Language and Literacy Development," in Beginning Literacy with Language: Young Children Learning at Home and at School, ed. David K. Dickinson and Patton O. Tabors (Baltimore: Brookes Publishing, 2001), 313-34.

18. Nonie K. Lesaux and Sky H. Marietta, Making Assessment Matter: Using Test Results to Differentiate Reading Instruction (New York: Guilford Press, 2012).

19. Paola Uccelli, "Beyond Chronicity: Evaluation and Temporality in Spanish-Speaking Children’s Personal Narratives," in Spanish Language Narration and Literacy Development, ed. Alyssa McCabe, Alison L. Bailey, and Gigliana Melzi (Cambridge: Cambridge University Press, 2008): 208.

20. "Teaching Children to Read: An Evidence-Based Assessment of the Scientific Research Literature on Reading and Its Implications for Reading Instruction," National Reading Panel (2000), accessed December 15, 2015, http://www.nichd.nih.gov/publications/nrp/report.cfm.

21. Developing Early Literacy: Report of the National Early Literacy Panel (Washington, DC: National Institute for Literacy and National Center for Family Literacy, 2008), http://lincs.ed.gov/publications/ pdf/NELPReport09.pdf.

22. Jeanne S. Chall, Stages of Reading Development (New York: McGraw-Hill, 1983).

23. Carol M. Connor et al., "Individualizing Student Instruction Precisely: Effects of Child x Instruction Interactions on First Graders' Literacy Development," Child Development 80 (2009): 77-100, doi: 10.1111/j.1467-8624.2008.01247.x.

24. Fiona M. Hollands et al., "Improving Early Literacy: Cost-Effectiveness Analysis of Effective Reading Programs," Center for Benefit-Cost Studies of Education, Teachers College, Columbia University, New York.

25. William E. Tunmer and James W. Chapman, Excellence and Equity in Literacy Education: The Case of New Zealand (Houndmills, UK: Palgrave Macmillan, 2015).

26. For additional evidence that constrained skills are more easily influenced by good-quality early childhood programs than are vocabulary or other unconstrained skills, see Jason T. Hustedt et al., "Kindergarten Readiness Impacts of the Arkansas Better Chance State Prekindergarten Initiative," Elementary School Journal 116 (2015): 198-216, doi: 10.1086/684105, which reports effects on print awareness that were more than three times larger than effects on vocabulary.

27. Loren M. Marulis and Susan B. Neuman, "The Effects of Vocabulary Intervention on Young Children's Word Learning: A Meta-Analysis," Review of Educational Research 80 (2010): 300-335, doi: $10.3102 / 0034654310377087$.

28. Susan B. Neuman, Ellen H. Newman, and Julie Dwyer, "Educational Effects of a Vocabulary Intervention on Preschoolers' Word Knowledge and Conceptual Development: A Cluster-Randomized Trial," Reading Research Quarterly 46 (2011): 249-72.

29. Christina Weiland and Hirokazu Yoshikawa, "Impacts of a Prekindergarten Program on Children's Mathematics, Language, Literacy, Executive Function, and Emotional Skills," Child Development 84 (2013): 2112-30, doi: 10.1111/cdev.12099. 
30. Christopher J. Lonigan and Anne E. Cunningham, "Significant Differences: Identifying the Evidence Base for Promoting Children's Early Literacy Skills in Early Childhood Education," in Early Childhood Literacy: The National Early Literacy Panel and Beyond, ed. Timothy Shanahan and Christopher J. Lonigan (Baltimore: Brookes Publishing, 2013), 161-93.

31. Vivian Gussin Paley, The Boy Who Would Be a Helicopter: The Uses of Storytelling in the Classroom (Cambridge, MA: Harvard University Press, 1990).

32. Ageliki Nicolopoulou et al., "Using a Narrative- and Play-Based Activity to Promote Low-Income Preschoolers' Oral Language, Emergent Literacy, and Social Competence," Early Childhood Research Quarterly 31 (2015): 147-62, doi: 10.1016/j.ecresq.2015.01.006.

33. David K. Dickinson, “Teachers' Language Practices and Academic Outcomes of Preschool Children," Science 333 (2011): 964-67, doi: 10.1126/science.1204526; David K. Dickinson and Michelle V. Porche, "Relation between Language Experiences in Preschool Classrooms and Children's Kindergarten and Fourth-Grade Language and Reading Abilities," Child Development 82 (2011): 870-86, doi: 10.1111/j.1467-8624.2011.01576.x; Perla B. Gámez and Susan C. Levine, "Oral Language Skills of Spanish-Speaking English Language Learners: The Impact of High-Quality Native Language Exposure," Applied Psycholinguistics 34 (2013), 673-96, doi: 10.1017/S0142716411000919; Janellen Huttenlocher et al., "Language Input and Child Syntax," Cognitive Psychology 45 (2002): 337-74, doi:10.1016/S0010-0285(02)00500-5.

34. W. Steven Barnett, "Better Teachers, Better Preschools: Student Achievement Linked to Teacher Qualifications," Preschool Policy Matters, Policy Brief No. 2 (New Brunswick, NJ: National Institute for Early Education Research, 2004); Catherine Snow, Peg Griffin, and M. Susan Burns, eds., Knowledge to Support the Teaching of Reading (San Francisco: John Wiley, 2005).

35. Robert C. Pianta et al., "Effects of Web-Mediated Professional Development Resources on TeacherChild Interactions in Pre-Kindergarten Classrooms," Early Childhood Research Quarterly 23 (2008): 431-51, doi: 10.1016/j.ecresq.2008.02.001.

36. Robert E. Slavin et al., "Effective Reading Programs for the Elementary Grades: A Best-Evidence Synthesis," Review of Educational Research 79 (2009), 1391-465, doi: 10.3102/0034654309341374.

37. Robert C. Pianta et al., "The Effects of Preschool Education: What We Know, How Public Policy Is or Is Not Aligned with the Evidence Base, and What We Need to Know," Psychological Science in the Public Interest 10 (2009): 49-88.

38. Susan B. Neuman and Linda Cunningham, "The Impact of Professional Development and Coaching on Early Language and Literacy Instructional Practices," American Educational Research Journal 46 (2009): 532-66, doi: 10.3102/0002831208328088.

39. Christina Yeager Pelatti, Jill M. Pentimonti, and Laura M. Justice, "Methodological Review of the Quality of Reach Out and Read: Does It 'Work'?” Clinical Pediatrics 53 (2014): 343-50, doi: 10.1177/0009922813507995.

40. Pamela C. High et al., "Literacy Promotion in Primary Care Pediatrics: Can We Make a Difference?" Pediatrics 105 (2000): 927-934.

41. Alan L. Mendelsohn et al., "Primary Care Strategies for Promoting Parent-Child Interactions and School Readiness in At-Risk Families: The Bellevue Project for Early Language, Literacy, and Education Success," Archives of Pediatrics and Adolescent Medicine 165 (2011): 33-41. doi: 10.1001/ archpediatrics.2010.254; Adriana Weisleder et al., "Promotion of Positive Parenting and Prevention of Socioemotional Disparities," Pediatrics 137 (2016): 1-9, doi: 10.1542/peds.2015-3239. 